\title{
BMJ Open Poor health, physical workload and occupational social class as determinants of health-related job loss: results from a prospective cohort study in the UK
}

\author{
Ranu Sewdas, ${ }^{1}$ Allard J van der Beek, ${ }^{1}$ Cecile R L Boot, ${ }^{1}$ Stefania D'Angelo, ${ }^{2}$ \\ Holly E Syddall, ${ }^{2}$ Keith T Palmer, ${ }^{2}$ Karen Walker-Bone ${ }^{2}$
}

To cite: Sewdas R, van der Beek AJ, Boot CRL, et al. Poor health, physical workload and occupational social class as determinants of healthrelated job loss: results from a prospective cohort study in the UK. BMJ Open 2019;9:e026423. doi:10.1136/ bmjopen-2018-026423

- Prepublication history for this paper is available online. To view these files, please visit the journal online (http://dx.doi. org/10.1136/bmjopen-2018026423).

Received 3 September 2018 Revised 30 April 2019

Accepted 12 June 2019

Check for updates

(C) Author(s) (or their employer(s)) 2019. Re-use permitted under CC BY-NC. No commercial re-use. See rights and permissions. Published by BMJ.

${ }^{1}$ Department of Public and Occupational Health, Amsterdam Public Health Research Institute, Amsterdam UMC, VU University Amsterdam, Amsterdam, The Netherlands

${ }^{2}$ MRC Lifecourse Epidemiology Unit, University of Southampton, Southampton, Hampshire, The United Kingdom

Correspondence to

Cecile R L Boot;

crl.boot@vumc.nl

\section{ABSTRACT}

Objectives The aims of the present study were to assess the association and interactions of physical workload and poor health with health-related job loss (HRJL) among older workers, and the association and interactions of occupational social class and poor health with HRJL. Methods Data were used from an existing prospective cohort study, Health and Employment after Fifty, where employed or self-employed workers aged 50-64 years $(n=4909)$ were followed-up between 2014 and 2016. Associations between potential determinants (self-perceived health status, physical workload and occupational social class) and 2-year HRJL were examined by Cox regression analyses. To study whether physical workload or occupational social class moderates the influence of poor health on HRJL, additive and multiplicative interactions were calculated.

Results Older workers with poor self-perceived health status had increased risk of HRJL during the 2-year follow-up period (men: HR 2.57 (95\% Cl: 1.68 to 3.92); women: HR 3.26 (95\%Cl: 2.33 to 4.55)). Furthermore, men with high physical workload were at increased risk for HRJL (HR 1.63 (95\%Cl: 1.09 to 2.43)). No significant interactions $(p<0.05)$ were identified between poor health and high physical workload, nor between poor health and lower occupational social class.

Conclusion Our study indicates that older workers in poor health, and older workers with a physically demanding job, are at increased risk of HRJL. Having a physically demanding job or working in routine/manual occupations does not moderate the association between poor health and HRJL.

\section{BACKGROUND}

Governments in many Western countries are developing policies to encourage older workers to remain longer in the labour market and delay retirement. In recent years, many countries have raised the age at which people can receive the basic state pension. Some governments have taken things even further. The government in the
Strengths and limitations of this study

- The present study used longitudinal data from a prospective cohort with a large sample size.

- We used a follow-up period of 2 years, and this timeframe is optimal to study the effect of poor health on health-related job loss.

- The analyses were adjusted for employment status, choice at work, job dissatisfaction, job insecurity, coping with mental demands, finances and depressive symptoms.

- Multiplicative as well as additive interactions were used to study the joint effect of the two risk factors.

- A limitation was the use of self-reported data for health status and physical workload.

UK, for example, has implemented other policies, which give people the opportunity to continue employment beyond the age of 65 years. ${ }^{1}$ In response, an increase has been observed in the proportion of older people working beyond traditional retirement age. ${ }^{2}$ However, during this phase of the life course, serious health problems become increasingly common as the risk of disability or chronic health conditions increases with age. ${ }^{3}$ Therefore, with an ageing labour force, it is important to focus on the relation between health and work participation.

Self-rated health is widely used in occupational health research and has been shown to be strongly predictive of disability, morbidity and mortality. ${ }^{4-6}$ A recent systematic review showed that, among older workers, poor self-rated health is a risk factor for job loss, through work disability, unemployment and early retirement. ${ }^{7}$ The relationship between self-rated health and employment is bidirectional, since poor health can negatively influence work participation, resulting in job loss, 
while poor working conditions can cause poor health..$^{8-10}$ It follows that the nature and direction of these relationships could differ between occupations among older workers. For example, manual workers in poor health might have a higher risk of job loss than office workers in poor health because of the generally higher physical demands of their jobs. However, current policies aimed at keeping older workers in the workforce tend not to differentiate, and thereby overlook potentially important health inequalities between people employed in different types of occupations..$^{1011}$

A considerable amount of literature has been published exploring the relationship between physical workload or occupational social class and job loss. Previous studies have suggested that low occupational social class or having a physically demanding job were associated with job loss via a work disability pension. ${ }^{12-14}$ Given that poor health is an important risk factor for job loss, researchers have not to date considered in much detail whether physical workload or occupational social class can moderate the influence of poor health on job loss. However, recent evidence suggested that educational attainment may be a moderator in this relationship. For example, van Zon et $a l^{15}$ showed that among older workers, lower educational attainment exacerbated the impact of poor mental health on unemployment. ${ }^{15}$ Another study found that the relation between educational level and disability pension could be explained by health factors, lifestyle factors and working conditions, such as having a physically demanding job. ${ }^{16}$ More knowledge about these interactions is needed to inform policy aimed at prolonging work participation at older ages.

We hypothesise therefore that for older workers, poor working conditions (low occupational social class or high physical workload) may interact with health status, resulting in a higher risk of job loss compared with those with better working conditions and similar health status. To test this hypothesis, therefore, our first aim was to assess the association and interactions of physical workload and poor health with health-related job loss (HRJL) among older workers. Our second aim was to study the associations and interactions of occupational social class and poor health with HRJL. Since systems used to define occupational social class are not synonymous with physical demands of work but also combine other information, such as skills, education and training, in this report, we have considered occupational social class and physical workload separately. ${ }^{17}$

\section{METHODS}

\section{Study population}

The present study followed Strengthening the Reporting of Observational Studies in Epidemiology guidelines. ${ }^{18}$ Data were taken from an existing prospective cohort study, Health and Employment after Fifty (HEAF). The HEAF cohort is a community-based sample of older people recruited from English general practices. Sampling for the cohort was through the registers of general practices (recognised to be very representative of the entire UK population). Many UK practices contribute their anonymised patient data to the Clinical Practice Research Datalink. Therefore, we sampled the registers of 24 such practices which offered a good geographical spread. In 2013-2014, a total of 8134 respondents (response rate 20.7\%) participated in the first wave of data collection. The recruited sample were older, better educated and wealthier than 50-64year olds in the population at large, but were representative with regard to employment status, ethnicity and marital status. ${ }^{19}$

Respondents aged 50-64 years completed annual questionnaires about their work and home circumstances in 2013-2014 (T0), 2015 (T1) and 2016 (T2). The baseline (T0), 1-year (T1) and 2-year (T2) follow-up data were included in the present study. From the 8134 participants at T0, 7303 participants responded at T1 and/or T2. In total, $\mathrm{n}=6285$ answered at T1 and T2; $\mathrm{n}=578$ answered at T1; $\mathrm{n}=440$ answered at T2. Details of recruitment and data collection have been published elsewhere. ${ }^{19}$

\section{Inclusion and exclusion criteria}

From the 7303 participants, those who reported that they were undertaking paid work at least 20 hours/week at baseline (this could be employed or self-employed work), and who provided dates of employment and HRJL during 2-year follow-up, were included in the current study $(\mathrm{n}=4909)$.

\section{Outcome variable}

The main outcome was time to first HRJL over 2 years of follow-up. Participants who reported that they were no longer working at follow-up were asked if they had stopped working 'mainly or partly' because of their health. Any participant who indicated 'yes' to this question was deemed to have experienced a HRJL, a method also used in other studies. ${ }^{20-22}$ Those who reported job loss unrelated to health or died within the 2-year follow-up period were censored. The date of the first HRJL was collected and used in these analyses.

\section{Independent variables}

Self-perceived health status

Self-rated health at baseline was measured using the question 'In general, would you say your health is: 'excellent', 'very good', 'good', 'fair' or 'poor'?'. ${ }^{4-6}$ This variable was categorised into two groups: (1) self-perceived health fair or poor, and (2) self-perceived health good, very good or excellent.

\section{Physical workload}

Physical workload at baseline was assessed by asking the following exposures of an average working day in the job: kneeling or squatting for longer than 1 hour per day in total, digging or shovelling, lifting weights of $10 \mathrm{~kg}$ or more by hand and hard physical work sufficient to make the respondent hot or sweaty. Respondents who answered 'yes' to one or more items were counted as 
having a physical workload, and compared with those who answered 'no' to all items.

\section{Occupational social class}

Subjects were asked about their occupation at baseline and responses were used to classify the jobs according to the National Statistics Socio-economic Classification (NS-SEC). ${ }^{17}$ The information required to create NS-SEC are occupation codes according to the Standard Occupation Classification 2010 (SOC 2010) and details of employment status: whether an employer, self-employed or employee; whether a supervisor and the number of employees at a workplace. ${ }^{17}$ Jobs were grouped into three categories: higher managerial, administrative and professional occupations; intermediate occupation or routine/ manual occupation.

\section{Potential confounders}

At baseline, information was collected on several potential confounders: age, gender, employment status (self-employed, employed with a company size $<500$ persons, employed with a company size $\geq 500$ persons), choice at work (rarely/never vs often/sometimes), job dissatisfaction (dissatisfied vs satisfied), job insecurity (insecure vs secure), coping with mental demands (with great difficulty vs easily) and finances (difficulties vs living comfortably). In addition, we have adjusted the models for depressive symptoms since these are recognised to influence self-rated health status and job loss. ${ }^{23}{ }^{24}$ Depressive symptoms were assessed with the 20-item Center for Epidemiologic Studies Depression Scale, which covers different domains: depressive mood, feelings of guilt and worthlessness, psychomotor retardation, loss of appetite and sleep disturbance. ${ }^{25} 26$ The range of the score falls between 0 and 60 , and a cut-off score of 16 was used to define mild depression. ${ }^{25} 26$

The following questions were used for the other variables: 'in your main job, do you have a choice in deciding what you do, how you do things or when you do things?' ('choice at work'); 'how satisfied have you been with your job as a whole, taking everything into consideration?' ('job dissatisfaction'); 'provided that you stay well, how secure do you feel your job is?' and 'how secure do you feel your job would be if you had an illness that kept you off work for 3 months or more?' ('job insecurity'); 'currently, how well do you cope with mental demands of your job?' ('coping with mental demands'); and 'how well do you feel you are managing financially these days?' ('finances').

\section{Analyses}

Summary statistics (means, SD, frequencies and percentages) were used to describe the baseline characteristics of the older workers.

\section{Associations}

Cox regression analyses were conducted to study associations between potential determinants (self-perceived health status, physical workload and occupational social class) and HRJL during a 2-year follow-up period. Hazard ratios (HR) and their corresponding 95\% confidence intervals (CI) were calculated. In model 1, analyses for the total sample were adjusted for age and gender, and separate models for men and women were adjusted for age. In model 2, analyses were additionally adjusted for employment status, choice at work, job dissatisfaction, job insecurity, coping with mental demands, finances and depressive symptoms. Participants were censored if they had a non-health related job loss or died.

\section{Interactions}

In general, from a public health perspective, additive interaction is more relevant than multiplicative interaction. ${ }^{27}$ The focus on multiplicative interaction is based on the immediate results (and CIs). ${ }^{27}$ However, when studying interaction, consideration of both additive and multiplicative measures of interaction has been advocated. ${ }^{27}$

\section{Multiplicative interactions}

To explore differences in the effect of poor health on HRJL among older workers who differ with respect to physical workload or occupational social class, an interaction term was coded between self-perceived health status and physical workload, or occupational social class, as appropriate. Multiplicative interaction was considered statistically significant if the $p$ value for the interaction term was below 0.05 .

\section{Additive interactions}

To study additive interaction, relative excess risk due to interaction (RERI) terms and their 95\% CI were calculated ( $\operatorname{se}^{27}$ for Stata code). The RERI is the excess risk attributed to interaction which is relative to the risk without an exposure. RERI was calculated with HRs as estimates of relative risks, for example, RERI $=\mathrm{HR}$ (poor health status+physicalworkload)-HR (poor health status+no physical workload)-HR (good health status+physicalworkload) +1 . If RERI is not equal to zero, an additive interaction is present; RERI can range from negative infinity (negative interaction, less than additivity) to positive infinity (positive interaction, more additivity). ${ }^{28}$

Furthermore, RERIs were calculated for occupational social class and self-perceived health status: HR (poor health status+routine/manual occupation)-HR (poor health status+highermanagerial)-HR (good health status+routine/manual occupation) +1 . The same RERI calculations were performed for poor health status and intermediate occupations with higher managerial occupations as a reference group.

All statistical analyses were conducted using Stata (release V.14.0).

\section{RESULTS}

The characteristics of the study respondents are presented in table 1. From the total population $(n=4909), 2363$ $(48.1 \%)$ were men. The average age was 57.8 years for 
Table 1 Characteristics of men and women in $\operatorname{HEAF}(n=4909)$

\begin{tabular}{|c|c|c|c|c|}
\hline & \multicolumn{2}{|c|}{ Men $(n=2363)$} & \multicolumn{2}{|c|}{ Women $(n=2546)$} \\
\hline & $\mathbf{N}^{*}$ & $\%$ & $\mathbf{N}^{*}$ & $\%$ \\
\hline Age (in years) & $57.8(4.2) \dagger$ & - & $57.1(3.9) \dagger$ & - \\
\hline Occupational social class & - & - & - & - \\
\hline Higher managerial & 989 & 41.9 & 1044 & 41.0 \\
\hline Intermediate occupations & 500 & 21.2 & 837 & 32.9 \\
\hline Routine/manual occupations & 840 & 35.6 & 647 & 25.4 \\
\hline Employment status & - & - & - & - \\
\hline Self-employed & 540 & 22.9 & 316 & 12.4 \\
\hline $\begin{array}{l}\text { Employed, company size: }<500 \\
\text { persons }\end{array}$ & 975 & 41.3 & 1252 & 49.2 \\
\hline $\begin{array}{l}\text { Employed, company size: } \geq 500 \\
\text { persons }\end{array}$ & 833 & 35.3 & 963 & 37.8 \\
\hline Heavy physical workload & 1093 & 46.3 & 727 & 28.6 \\
\hline Rarely or never choice at work & 393 & 16.6 & 557 & 21.9 \\
\hline Job dissatisfaction & 171 & 7.2 & 155 & 6.1 \\
\hline Job insecurity & 1136 & 48.1 & 1179 & 46.3 \\
\hline $\begin{array}{l}\text { Difficulty coping with work's mental } \\
\text { demands }\end{array}$ & 670 & 28.4 & 846 & 33.2 \\
\hline Difficulties with finances & 157 & 6.6 & 218 & 8.6 \\
\hline $\begin{array}{l}\text { Self-perceived health status, fair/ } \\
\text { poor }\end{array}$ & 404 & 17.1 & 430 & 16.9 \\
\hline $\begin{array}{l}\text { Depressive symptoms, CESD- } \\
\text { score } \geq 16\end{array}$ & 456 & 19.3 & 664 & 26.1 \\
\hline
\end{tabular}

${ }^{*}$ For some variables, data were missing for a maximum of 45 men and 56 women.

†Mean and SD.

Percentage values are relative to total sample size for each gender group.

HEAF, Health and Employment after Fifty.

men and 57.1 years for women. At baseline, 404 (17.1\%) men and $430(16.9 \%)$ women had poor self-perceived health status, and 1093 (46.3\%) men and 727 (28.6\%) women reported a heavy physical workload. Most men were employed in higher managerial occupations $(n=989$ $(41.9 \%))$, followed by routine/manual occupations $(\mathrm{n}=840(35.6 \%))$ and intermediate occupations $(\mathrm{n}=500$ $(21.2 \%))$. Most women were employed in higher managerial occupations $(\mathrm{n}=1044(41.0 \%))$, followed by intermediate occupations $(\mathrm{n}=837(32.9 \%))$ and routine/ manual occupations $(\mathrm{n}=647(25.4 \%))$.

During a 2-year follow-up period, 283 respondents (107 men, 176 women) left their job partly or wholly for a health reason. Of the 283 respondents with HRJL, 125 described themselves as having retired (44\%), 39 became unemployed (14\%), eight reported a mixture of both (3\%), and 111 returned to work at some point after HRJL $(39 \%)$.

\section{Associations}

Table 2 presents main effect associations between poor health status, physical workload and occupational social class with 2-year HRJL.
In fully adjusted models, older workers who reported poor health were at an increased risk of HRJL (men: HR 2.57 (95\%CI: 1.68 to 3.92); for women: HR 3.26 (95\% CI: 2.33 to 4.55$)$ ). Furthermore, men with high physical workload were at increased risk for HRJL (HR 1.63 (95\% CI: 1.09 to 2.43)). Women with high physical workload were at increased risk of HRJL in the age-adjusted analysis (model 1, HR 1.63 (95\% CI: 1.20 to 2.20 )), but full adjustment attenuated this relationship (model 2). Regarding occupational social class, men with routine/ manual occupations were at increased risk of HRJL in age-adjusted analysis, but not fully-adjusted analysis. No significant associations were found between occupational social class and HRJL for women.

\section{Multiplicative interactions}

Table 2 also presents p-values for the interaction terms between poor health and physical workload, and poor health and occupational social class; none were significant at the $5 \%$ level $(p>0.05)$.

\section{Additive interactions}

No statistically significant RERIs were found for the three interaction effects for men and women combined 


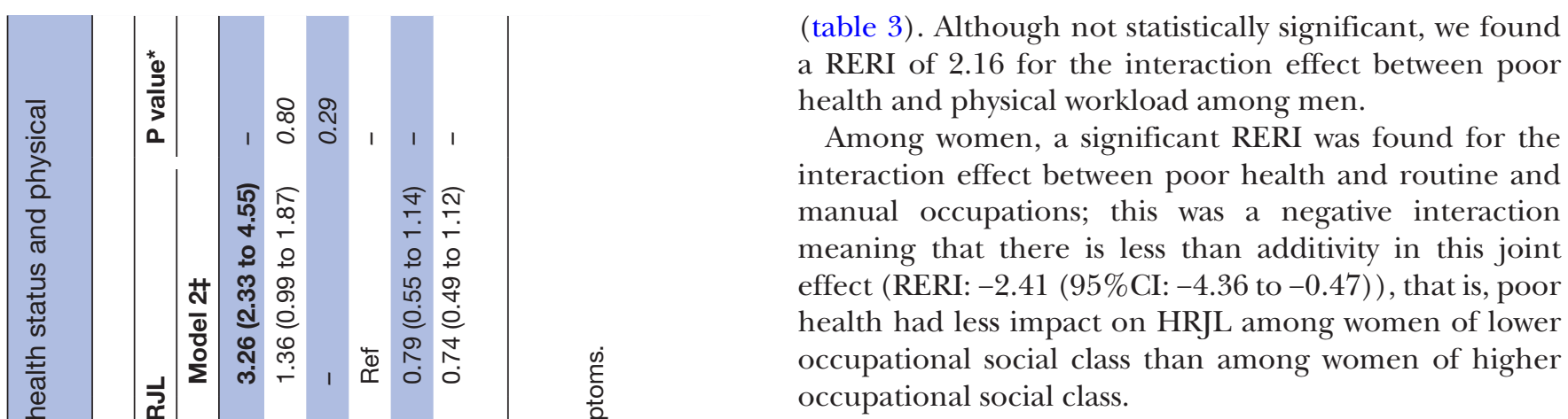

\section{DISCUSSION}

Male and female older workers with poor self-perceived health status had increased risk of 2-year health-related job loss (HR 2.57 (95\% CI: 1.68 to 3.92) and HR 3.26 (95\% CI: 2.33 to 4.55 ), respectively). Furthermore, men with a physically demanding job had higher risk of health-related job loss (HR 1.63 (95\%CI: 1.09, 2.43)). For men, no significant interactions were found between poor health and physical workload, nor between poor health and lower occupational social class. For women, we showed that the combination of working in higher managerial, administrative and professional occupations together with poor health increased the risk of health-related job loss.

Corresponding to previous studies, we have shown that having a physically demanding workload was a risk factor for job loss. ${ }^{1329}$ According to the model of ageing and physical workload, the consequences of ageing can disrupt the balance between physical workload and physical work capacity caused by three determinants of ageing: biological ageing, diseases and lifestyle. ${ }^{30}$ Accordingly, among the older male workers in this study, the strong association between heavy physical workload and HRJL might be explained by an imbalance between physical workload and physical work capacity. Evidence supporting this came from a previous study which found that high physical demands at work was a predictor for early exit from work for older workers with chronic diseases, while it was not a predictor for those without chronic diseases. ${ }^{31}$ Preventive measures to reduce the risk of job loss among older male workers with occupations that require high physical demands should focus on reducing physical workload as well as tackling the age-related decrease in physical work capacity, perhaps by introduction of, for example, health promotion programmes that are targeted on, for instance, lifestyle factors, such as improving physical activity during leisure time. ${ }^{30}$

As we expected and in line with previous studies, poor self-reported health was associated with job loss, ${ }^{732}$ and this association was stronger among women. Although both determinants were significant, we found no interaction effects between poor health and physical workload. This may be explained by a possible healthy worker selection effect among the population in the current study. ${ }^{33}$ The workers in our study population were able to work 
Table 3 Associations and RERI of poor health, occupational social class and physical workload with 2-year HRJL

\begin{tabular}{|c|c|c|c|c|c|c|}
\hline \multirow{2}{*}{$\begin{array}{l}\text { HRs }(95 \% \mathrm{Cl}) \text { representing } \\
\text { joint effects }\end{array}$} & \multicolumn{2}{|c|}{ Total sample } & \multicolumn{2}{|l|}{ Men } & \multicolumn{2}{|l|}{ Women } \\
\hline & $\mathbf{N}$ & & $\mathbf{N}$ & & $\mathbf{N}$ & \\
\hline $\begin{array}{l}\text { Good health and no physical } \\
\text { workload }\end{array}$ & 2598 & Ref & 1066 & Ref & 1532 & \\
\hline $\begin{array}{l}\text { Good health and physical } \\
\text { workload }\end{array}$ & 1414 & $1.48(1.07$ to 2.04$)$ & 869 & 1.47 (0.88 to 2.45$)$ & 545 & 1.44 (0.94 to 2.22$)$ \\
\hline $\begin{array}{l}\text { Poor health and no physical } \\
\text { workload }\end{array}$ & 454 & $4.14(2.99$ to 5.74$)$ & 192 & 3.29 (1.75 to 6.19$)$ & 262 & 4.52 (3.09 to 6.64$)$ \\
\hline $\begin{array}{l}\text { Poor health and physical } \\
\text { workload }\end{array}$ & 380 & 6.06 (4.40 to 8.35$)$ & 212 & 5.92 (3.53 to 9.92) & 168 & 6.06 (4.01 to 9.15$)$ \\
\hline $\begin{array}{l}\text { RERI }(95 \% \mathrm{Cl}) \text { for poor health } \\
\text { and physical workload }\end{array}$ & & $1.44(-0.39$ to 3.27$)$ & & $2.16(-0.60$ to 4.91$)$ & & $1.09(-1.34$ to 3.52$)$ \\
\hline $\begin{array}{l}\text { HRs }(95 \% \mathrm{Cl}) \text { representing } \\
\text { joint effects }\end{array}$ & $\mathbf{N}$ & & $\mathbf{N}$ & & $\mathbf{N}$ & \\
\hline $\begin{array}{l}\text { Good health and higher } \\
\text { managerial }\end{array}$ & 1740 & Ref & 846 & Ref & 894 & Ref \\
\hline $\begin{array}{l}\text { Good health and intermediate } \\
\text { occupations }\end{array}$ & 1093 & $0.46(0.31$ to 0.69$)$ & 398 & $0.32(0.14$ to 0.74$)$ & 695 & $0.55(0.35$ to 0.88$)$ \\
\hline $\begin{array}{l}\text { Poor health and higher } \\
\text { managerial }\end{array}$ & 280 & 3.51 (2.54 to 4.86$)$ & 136 & 2.03 (1.10 to 3.73$)$ & 144 & 4.75 (3.21 to 7.03$)$ \\
\hline $\begin{array}{l}\text { Poor health and intermediate } \\
\text { occupations }\end{array}$ & 224 & 3.05 (2.12 to 4.37$)$ & 96 & 1.55 (0.72 to 3.37$)$ & 128 & 4.11 (2.70 to 6.25$)$ \\
\hline $\begin{array}{l}\text { RERI }(95 \% \mathrm{Cl}) \text { for poor health } \\
\text { and intermediate occupations }\end{array}$ & & $0.07(-1.36$ to 1.51$)$ & & $0.20(-1.45$ to 1.86$)$ & & $-0.20(-2.39$ to 2.00$)$ \\
\hline $\begin{array}{l}\text { HRs }(95 \% \mathrm{Cl}) \text { representing } \\
\text { joint effects }\end{array}$ & $\mathbf{N}$ & & $\mathbf{N}$ & & $\mathbf{N}$ & \\
\hline $\begin{array}{l}\text { Good health and higher } \\
\text { managerial }\end{array}$ & 1740 & Ref & 846 & Ref & 894 & Ref \\
\hline $\begin{array}{l}\text { Good health and routine/ } \\
\text { manual occupations }\end{array}$ & 1140 & 0.97 (0.70 to 1.34$)$ & 665 & 1.36 (0.83 to 2.22$)$ & 475 & 0.75 (0.47 to 1.19$)$ \\
\hline $\begin{array}{l}\text { Poor health and higher } \\
\text { managerial }\end{array}$ & 280 & $4.13(2.97$ to 5.76$)$ & 136 & 3.23 (1.69 to 6.17$)$ & 144 & $4.66(3.17$ to 6.85$)$ \\
\hline $\begin{array}{l}\text { Poor health and routine/ } \\
\text { manual occupations }\end{array}$ & 323 & 3.11 (2.21 to 4.38$)$ & 167 & 5.41 (3.27 to 8.94) & 156 & 2.00 (1.20 to 3.29$)$ \\
\hline $\begin{array}{l}\text { RERI }(95 \% \mathrm{Cl}) \text { for poor health } \\
\text { and routine and manual } \\
\text { occupations }\end{array}$ & & $-1.00(-2.56$ to 0.57$)$ & & $1.82(-1.04$ to 4.68$)$ & & $-2.41(-4.36$ to -0.47$)$ \\
\hline
\end{tabular}

Analyses are adjusted for age and the analysis for the total population was also adjusted for gender. Bold values significant at 0.05 .

HRJL, health-related job loss; Ref, reference category; RERI, relative excess risk due to interaction.

until the age of 50 years or older; those with serious health problems and physical workload are perhaps selected out of their workplaces by the age of 50 years. Furthermore, the current study population were better educated and wealthier compared with the 50-64-year-age group in the population at large, and this could also explain the absence of an interaction effect. ${ }^{19}$

Contrary to the current results, previous studies have found a relation between occupational class differences and employment outcomes. ${ }^{12}{ }^{34}$ This may be explained by the classification systems used for occupational social class in the present study and the previous studies
(NS-SEC vs ISCO-2001). In the present study, NS-SEC is an occupation-based social class scheme and the lowest occupational social class does not necessarily correspond with exposure to physical workload. Changes in the nature and structure of occupations, mainly due to mechanisation and automation, may have contributed to making these distinctions outdated, so that the lowest occupational social class does not so closely relate to what used to be considered 'typical' manual jobs or blue collar jobs. ${ }^{17}$ In addition, a classification system with three categories might result in too many different jobs in one category, and this could hide the risks of specific jobs. Such 
an effect would also explain the absence of a significant association between occupational social class and HJRL while we found a significant association between physical workload (defined through self-reported physical exposure information) and HRJL.

Regarding the interaction effects between poor health and occupational social class, the present study found a negative additive interaction term (ie, preventive mechanism) among women for the joint effect of poor health and routine/manual occupations. This indicates a higher risk of HRJL for women with poor health working in higher managerial occupations compared with those in routine/ manual occupations since higher managerial, administrative and professional occupations was used as the reference category. This could be explained perhaps by the high mental demands required for these types of occupation or could result from a combination of poor working conditions together with high physical demands, for example, among women working as nurses, ${ }^{35}$ a group of workers who are classified in this occupational social class. Certainly, a previous study among nurses found that low influence at work combined with high physical demands increased the probability of becoming disability pensioned. ${ }^{36}$ Our results indicate that working in higher managerial, administrative and professional occupations, such as nursing, in combination with self-perceived poor health status could increase the risk of HRJL among women.

The current study benefits from having data on HRJL among participants over 2 years of follow-up, especially given that a previous study suggested that the strongest effect of poor health on exit from work was observed in the year before the transition. ${ }^{37}$ However, with regard to physical workload, no information was available on the total number of years of 'exposure' to physical workload. It could be possible that other effects could have been found when years of exposure were taken into account.

A strength of the present study is the use of longitudinal data from a prospective cohort with a large sample size. A second strength is that we took into account multiplicative as well as additive interactions to study the joint effect of two risk factors. However, this study has also some limitations. First, at baseline, the overall response rates were low. The population in the current study were older, better educated and wealthier compared with the 50-64-year-age group in the population at large. However, our population was representative with regard to employment status, ethnicity and marital status, and it included participants from most regions in the UK. ${ }^{19}$ Second, in the present study, HRJL does not necessarily correspond to permanent job loss due to poor health. Approximately $39 \%$ of the people with HRJL returned to work after some time. Nevertheless, studying HRJL, whatever the subsequent outcome, is relevant since these workers would be vulnerable for a period of time after they stopped working (temporarily) due to health problems, which is also known as the 'off work' phase in the return to work process. ${ }^{38}$
Another limitation was the use of self-reported data. Self-rated health status cannot be said to be a measure of the objective health status of a person, but is rather a subjective measurement as perceived and reported by that person. Despite this, according to van Rijn et al, ${ }^{7}$ self-perceived health status shows stronger associations with job loss when compared with other health measures, such as mental health or chronic diseases, and has been shown to be a valid measure of health. ${ }^{4-6}{ }^{39}$ It is plausible that poor self-reported health is a strong indicator for job loss because it also reflects a persons' judgement about the incompatibility of their self-perceived health status with the demands of their job. ${ }^{40}$ Certainly, it is important to bear in mind that a specific physical health condition for example, dominant sided rotator cuff tear will have differential work impacts upon, for example, a painter/decorator than a desk-based administrator. In contrast, people with pronounced physical conditions such as rheumatoid arthritis may not report poor self-rated health status. In the current study, therefore, it is interesting that questions about health status were asked at baseline when all participants were in paid work $>20$ hours/week and everybody continued to contribute data until they exited work (for health or any other reason) or die. Therefore, our results further elucidate the relevance of self-rated health since we have been able to compare the risk of HRJL according to the information about work status within categories of self-perceived health at baseline.

Regarding physical workload, only self-reported measurement of physical workload were available in the present study. Previous studies have shown that self-reported physical workloads are prone to bias and are less reliable than objective measurements for physical workload. ${ }^{41}{ }^{42}$ However, for large-scale epidemiological studies such as this one, objective measurements are not feasible and previous studies have shown that self-reported measurement of physical workload is a useful method to classify individuals into groups with regard to their physical workload. ${ }^{43}$

With regard to policy reforms aimed at increasing the official retirement age, one should consider whether everyone can sustain their work ability at older ages. Our study indicates that a vulnerable group exists of older workers in poor health, and older workers with a physically demanding job. Correspondingly, previous studies have demonstrated the role of working conditions contributing to health inequalities among employees. ${ }^{44-46}$ The results of the present study may help us to understand how we can enable older workers to remain active in paid employment. We suggest implementing workplace interventions that include monitoring the health of older workers. Moreover, we recommend considering adjustment of the work environment among the older working population with regard to physical workload to maximise the possibility to continue working to older ages. Further research is needed to confirm whether these suggested interventions could contribute to sustainable employability of 
the older working population. Furthermore, further research is required to study the role of other working conditions related to higher managerial, administrative and professional occupations, such as poor psychosocial work characteristics at work that may contribute to job loss.

In summary, this study among older workers has shown that poor health as well as physical workload were risk factors for health-related job loss. Having a physically demanding job or working in routine/ manual occupations does not moderate the association between poor health and health-related job loss. For women, we showed that the combination of working in higher managerial, administrative and professional occupations together with poor health increased the risk of health-related job loss. Intervention studies are needed to investigate the feasibility of intervening to improve health and reduce physical workload among the older working population.

Contributors RS, AvdB, CB, SD'A, KP and KWB contributed to design of the paper. The authors RS, SD'A and HS contributed to the data analysis. RS participated in drafting the article. Finally, AvdB, CB, SD'A, HS, KP and KWB revised the article critically for important intellectual content.

Funding The authors have not declared a specific grant for this research from any funding agency in the public, commercial or not-for-profit sectors.

Competing interests None declared.

Patient consent for publication Not required.

Ethics approval Ethical approval was received from the NHS Research Ethics Committee North West-Liverpool East.

Provenance and peer review Not commissioned; externally peer reviewed.

Data sharing statement Extra data are available by emailing the corresponding author.

Open access This is an open access article distributed in accordance with the Creative Commons Attribution Non Commercial (CC BY-NC 4.0) license, which permits others to distribute, remix, adapt, build upon this work non-commercially, and license their derivative works on different terms, provided the original work is properly cited, appropriate credit is given, any changes made indicated, and the use is non-commercial. See: http://creativecommons.org/licenses/by-nc/4.0/.

\section{REFERENCES}

1. Department for Work and Pensions, Department of Health. No one written off: reforming welfare to reward responsibility. Public consultation. London: The Stationery Office, 2008:978.

2. Office for National Statistics. Pension trends. Chapter 4: the labour market and retirement. 2013 http//www.ons.gov.uk/ons/dcp171766_ 297899.pdf.

3. Harbers MM, Achterberg PW. Europeans of retirement age: chronic diseases and economic activity. Bilthoven: RIVM, 2012.

4. Idler EL, Russell LB, Davis D. Survival, functional limitations, and self-rated health in the NHANES I Epidemiologic Follow-up Study, 1992. First National Health and Nutrition Examination Survey. Am J Epidemiol 2000;152:874-83.

5. Kaplan GA, Goldberg DE, Everson SA, et al. Perceived health status and morbidity and mortality: evidence from the Kuopio ischaemic heart disease risk factor study. Int J Epidemiol 1996;25:259-65.

6. Wu S, Wang R, Zhao Y, et al. The relationship between self-rated health and objective health status: a population-based study. BMC Public Health 2013;13:320.

7. van Rijn RM, Robroek SJ, Brouwer S, et al. Influence of poor health on exit from paid employment: a systematic review. Occup Environ Med 2014;71:295-301.

8. van den Berg T, Schuring M, Avendano M, et al. The impact of ill health on exit from paid employment in Europe among older workers. Occup Environ Med 2010;67:845-52.
9. Weyers S, Peter R, Boggild H, et al. Psychosocial work stress is associated with poor self-rated health in Danish nurses: a test of the effort-reward imbalance model. Scand J Caring Sci 2006;20:26-34.

10. Kaikkonen R, Rahkonen O, Lallukka T, et al. Physical and psychosocial working conditions as explanations for occupational class inequalities in self-rated health. Eur J Public Health 2009;19:458-63.

11. Acheson D. The Stationary Office. Independent inquiry into inequalities in health. London, 1998. http//www.archive.officialdocuments.co.uk/document/doh/ih/ih.htm.

12. Leinonen $\mathrm{T}$, Pietiläinen $\mathrm{O}$, Laaksonen $\mathrm{M}$, et al. Occupational social class and disability retirement among municipal employees-the contribution of health behaviors and working conditions. Scand J Work Environ Health 2011;37:464-72.

13. Järvholm B, Stattin M, Robroek SJ, et al. Heavy work and disability pension - a long term follow-up of Swedish construction workers. Scand J Work Environ Health 2014;40:335-42.

14. Schuring M, Robroek SJ, Otten FW, Otten Ferdy WJ, et al. The effect of ill health and socioeconomic status on labor force exit and re-employment: a prospective study with ten years follow-up in the Netherlands. Scand J Work Environ Health 2013;39:134-43.

15. van Zon SKR, Reijneveld SA, Mendes de Leon CF, et al. The impact of low education and poor health on unemployment varies by work life stage. Int J Public Health 2017;62:997-1006.

16. Robroek SJ, Rongen A, Arts $\mathrm{CH}$, et al. Educational Inequalities in Exit from Paid Employment among Dutch Workers: The Influence of Health, Lifestyle and Work. PLoS One 2015;10:e0134867.

17. Office for National Statistics. The National statistics socioeconomic classification: (rebased on the SOC2010) user manual. 2010.

18. Vandenbroucke JP, von Elm E, Altman DG, et al. Strengthening the Reporting of Observational Studies in Epidemiology (STROBE): explanation and elaboration. PLoS Med 2007;4:e297.

19. Palmer KT, Walker-Bone K, Harris EC, et al. Health and Employment after Fifty (HEAF): a new prospective cohort study. BMC Public Health 2015;15:1071.

20. Solomon C, Poole J, Palmer KT, et al. Health-related job loss: findings from a community-based survey. Occup Environ Med 2007;64:144-9.

21. Haahr JP, Frost $P$, Andersen JH. Predictors of health related job loss: a two-year follow-up study in a general working population. $J$ Occup Rehabil 2007;17:581-92.

22. Palmer KT, D'Angelo S, Harris EC, et al. Frailty, prefrailty and employment outcomes in Health and Employment After Fifty (HEAF) Study. Occup Environ Med 2017;74:476-82.

23. Bültmann U, Christensen KB, Burr H, et al. Severe depressive symptoms as predictor of disability pension: a 10-year follow-up study in Denmark. Eur J Public Health 2008;18:232-4.

24. Mulsant BH, Ganguli M, Seaberg EC. The relationship between self-rated health and depressive symptoms in an epidemiological sample of community-dwelling older adults. J Am Geriatr Soc 1997;45:954-8.

25. Andresen EM, Malmgren JA, Carter WB, et al. Screening for Depression in Well Older Adults: Evaluation of a Short Form of the CES-D. Am J Prev Med 1994;10:77-84.

26. Radloff LS. The CES-D scale a self-report depression scale for research in the general population. Appl Psychol Meas 1977;1:385-401.

27. van der Weele TJ, Knol MJ. A tutorial on interaction. Epidemiologic Methods 2014;3:33-72.

28. Knol MJ, VanderWeele TJ, Groenwold RH, et al. Estimating measures of interaction on an additive scale for preventive exposures. Eur J Epidemiol 2011;26:433-8.

29. Kjellberg K, Lundin A, Falkstedt D, et al. Long-term physical workload in middle age and disability pension in men and women: a follow-up study of Swedish cohorts. Int Arch Occup Environ Health 2016:89:1239-50.

30. de Zwart BC, Frings-Dresen MH, van Dijk FJ. Physical workload and the aging worker: a review of the literature. Int Arch Occup Environ Health 1995;68:1-12.

31. Boot CR, Deeg DJ, Abma T, et al. Predictors of having paid work in older workers with and without chronic disease: a 3-year prospective cohort study. J Occup Rehabil 2014;24:563-72.

32. Reeuwijk KG, van Klaveren D, van Rijn RM, et al. The influence of poor health on competing exit routes from paid employment among older workers in 11 European countries. Scand J Work Environ Health 2017;43:24-33.

33. McMichael AJ. Standardized mortality ratios and the "healthy worker effect": scratching beneath the surface. J Occup Environ Med 1976;18:165-8. 
34. Virtanen M, Oksanen T, Pentti J, et al. Occupational class and working beyond the retirement age: a cohort study. Scand J Work Environ Health 2017;43:426-35.

35. Aittomäki A, Lahelma E, Roos E, et al. Gender differences in the association of age with physical workload and functioning. Occup Environ Med 2005;62:95-100.

36. Friis $\mathrm{K}$, Ekholm O, Hundrup YA. The relationship between lifestyle, working environment, socio-demographic factors and expulsion from the labour market due to disability pension among nurses. Scand $J$ Caring Sci 2008;22:241-8.

37. Leino-Arjas P, Liira J, Mutanen P, et al. Predictors and consequences of unemployment among construction workers: prospective cohort study. BMJ 1999;319:600-5.

38. Young AE, Roessler RT, Wasiak R, et al. A developmental conceptualization of return to work. J Occup Rehabil 2005;15:557-68.

39. Singh-Manoux A, Martikainen P, Ferrie J, et al. What does self rated health measure? Results from the British Whitehall II and French Gazel cohort studies. J Epidemiol Community Health 2006;60:364-72.
40. Idler EL, Benyamini Y. Self-rated health and mortality: a review of twenty-seven community studies. J Health Soc Behav 1997;38:21-37.

41. Berntsen S, Hageberg R, Aandstad A, et al. Validity of physical activity monitors in adults participating in free-living activities. $\mathrm{Br} \mathrm{J}$ Sports Med 2010;44:657-64.

42. Kwak L, Proper KI, Hagströmer M, et al. The repeatability and validity of questionnaires assessing occupational physical activity--a systematic review. Scand J Work Environ Health 2011;37:6-29.

43. Viikari-Juntura E, Rauas S, Martikainen R, et al. Validity of self-reported physical work load in epidemiologic studies on musculoskeletal disorders. Scand J Work Environ Health 1996;22:251-9.

44. Lundberg $\mathrm{O}$. Causal explanations for class inequality in health-an empirical analysis. Soc Sci Med 1991;32:385-93.

45. Marmot MG, Bosma $\mathrm{H}$, Hemingway $\mathrm{H}$, et al. Contribution of job control and other risk factors to social variations in coronary heart disease incidence. Lancet 1997;350:235-9.

46. Schrijvers CT, van de Mheen HD, Stronks K, et al. Socioeconomic inequalities in health in the working population: the contribution of working conditions. Int J Epidemiol 1998;27:1011-8. 